\title{
1
}

\section{TRABALHO E EDUCAÇÃO: DEBATES EM TORNO DO PRINCÍPIO EDUCATIVO E DAS POLÍTICAS EDUCACIONAIS PARA O ENSINO MÉDIO DE JOVENS E ADULTOS'1}

\author{
Leonardo Dorneles Gonçalves ${ }^{2}$ \\ Simone Gonçalves da Silva ${ }^{3}$
}

\section{Resumo}

Abordamos a relação de trabalho e educação no ensino médio da Educação de Jovens e Adultos (EJA) e como se expressa o princípio educativo neste nível e modalidade. Sendo um estudo teórico e bibliográfico, nos valemos do debate da educação e trabalho no campo marxista. Analisamos como o princípio educativo se manifesta no ensino médio da EJA. As políticas educacionais para o ensino médio da EJA são complexas, pois há distanciamento entre as bases conceituais e o discurso oficial. Sustentam um projeto baseado na acumulação flexível, exigindo um trabalhador polivalente e induzem a formação para o mercado. O texto foi produzido no âmbito das discussões sobre as aproximações das pesquisas realizadas pelos autores em suas dissertações e teses.

Palavras-chave: Ensino Médio; Educação de Jovens e Adultos; Políticas Educacionais.

\section{TRABAJO Y EDUCACIÓN: DEBATES EN TORNO DEL PRINCIPIO EDUCATIVO Y DE LAS POLÍTICAS EDUCATIVAS PARA LA ENSEÑANZA MEDIO DE JÓVENES Y ADULTOS}

\section{Resumen}

Abordamos la relación de trabajo y educación en la secundaria de EJA y cómo si expresa el principio educativo en este nivel y modalidad. Siendo un estudio teórico y bibliográfico, nos valemos del debate de la educación y trabajo en el campo marxista. Analizamos cómo el principio educativo si manifiesta en la secundaria de EJA. Las políticas educativas para la secundaria de EJA son complejas, pues hay distanciamiento entre las bases conceptuales y el discurso oficial. Apoyan un proyecto basado en la acumulación flexible, exigiendo un trabajador polivalente/multifuncional y induce la formación para el mercado.

Palabras clave: Secundaria; EJA; Políticas Educativas.

\section{WORK AND EDUCATION: DEBATES ON THE EDUCATIONAL PRINCIPLE AND EDUCATIONAL POLICIES FOR HIGH SCHOOL OF YOUTH AND ADULTS}

\section{Abstract}

We approach the relation of work and education in the high school of the EJA and how the educational principle is expressed in this level and modality. Being a theoretical and bibliographical study, we use

\footnotetext{
1 Recebido em 13/05/2019. Primeira avaliação: 21/05/2019. Segunda avaliação: 21/05/2019. Aprovado em 12/08/2019. Publicado em 27/09/2019. DOI: https://doi.org/10.22409/tn.17i34.p38056.

2 Doutor em Educação (UFPel). Professor Adjunto de Políticas Educacionais - Departamento de Ensino, Faculdade de Educação da Universidade Federal de Pelotas. dorneles05@gmail.com ORCID: https://orcid.org/0000-0001-8093-8493

3 Doutora em Educação (UFPel). Professora do Pós-Graduação em Educação da Universidade do Oeste de Santa Catarina. silva.simonegon@gmail.com ORCID:https://orcid.org/0000-0001-51592454
} 
the debate of education and work in the Marxist field. We analyze how the educational principle manifests itself in the high school of the EJA. The educational policies for high school of the EJA are complex, because there is a distance between the conceptual bases and the official discourse. They support a project based on flexible accumulation, requiring a multipurpose worker and inducing training for the market.

Keywords: High School; Youth and Adult Education; Educational Policies

\section{Introdução}

O mundo atual tem convivido com rápidas e radicais transformações no campo do trabalho. Durante os primeiros três terços do século XX, conservou-se a separação entre pensamento e ação, direcionando uma pedagogia tecnicista centrada ora em conhecimentos intelectuais, ora nas atividades mecanizadas e manuais, reproduzindo um modelo de formação educacional/escolar dicotômico que, em síntese, atendeu as necessidades do regime de acumulação taylorista/fordista. Por isso, nos deparamos com transformações no processo de produção que implicam em novas exigências à escolarização, cuja finalidade é a formação de trabalhadores de um novo tipo (NEVES, 2000), mais adequado à aquisição de competências e habilidades do aprender a aprender (SAVIANI, 2010). Esse novo tipo, por sua vez, demanda uma nova perspectiva educativa ancorada em novas práticas e ordenamentos pedagógicos que oportunizem resultados imediatamente aptos aos interesses do mercado. A atualidade da divisão social e técnica do trabalho, reforçada pela prática contraditória da competitividade, da eficiência e do individualismo, sustenta este ideário.

Neste sentido, o processo da formação escolar tem apresentado credenciais que possibilitam a entrada de jovens e adultos no mercado de trabalho, ainda que isso não seja o suficiente para garantir a permanência e/ou manutenção neste mesmo mercado. Prova disso são os recentes investimentos em capacitação técnica de curta duração ${ }^{4}$, que se apresentam através da promessa de empregabilidade e da possibilidade de ascensão social, mas que nem sempre se constituem como efetiva entrada ao mercado, configurando na certificação um simulacro formativo (RUMMERT; ALGEBAILE; VENTURA, 2013). Isso ocorre, justamente, porque a dinâmica que determina o aumento ou diminuição da contratação da força de trabalho está atrelada ao aumento das taxas de lucro, o que, em si, não apresenta uma relação direta com a escolaridade. Independentemente disso, inúmeras

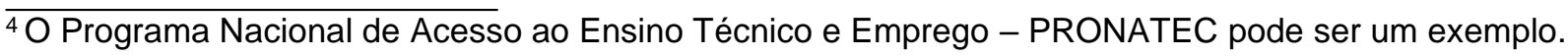


políticas públicas foram criadas como forma de garantir a ampliação do acesso à educação enquanto um direito subjetivo, conforme preconiza a Constituição Federal de 1988. Além disso, possibilitou aos jovens e adultos trabalhadores a certificação do processo educacional e, em certa medida, a formação de competências que os torne minimamente aptos às ocupações e ao emprego.

Entretanto, ao mesmo tempo em que se pode interpretar a existência de políticas públicas destinadas à educação de jovens e adultos, em seu sentido amplo, como uma resposta na forma de atendimento à necessidade de escolarização desses grupos que não tiveram acesso à escola em tempo previsto na lei, também é possível ler tal ampliação da oferta, por meio destas políticas, como expressão da educação como condição para empregabilidade. De uma forma ou de outra, parecenos que os vínculos da formação dos jovens e adultos, sobretudo em nível médio, no atual estágio de desenvolvimento, expressam os interesses do tipo de trabalhador que as formas do capital demandam, ainda que essas formas não sejam notadamente perceptíveis em um primeiro momento, justamente porque se transvestem do discurso confuso pela democratização do acesso.

Sendo assim, neste texto, debatemos as relações entre trabalho, entendido em suas diversas e contraditórias manifestações, e educação, apresentada a partir dos direcionamentos políticos, principalmente aqueles aspectos que incidem diretamente na formação de jovens e adultos trabalhadores em nível médio. Este texto, então, caracteriza-se como um estudo teórico e bibliográfico que quer compreender a relação de trabalho e educação no ensino médio de educação de jovens e adultos, e como se expressa o princípio educativo neste nível e nesta modalidade. Para tanto, vale-se inicialmente do debate em torno do tema a partir de alguns autores para, posteriormente, visualizar as formas como o princípio educativo ${ }^{5}$ se manifesta no processo histórico do ensino médio de jovens eadultos.

\footnotetext{
${ }^{5} \mathrm{~A}$ discussão de Trabalho como princípio educativo no campo de estudos no cenário brasileiro foi e vem sendo apreciado por um considerável conjunto de autores, entre os quais poderíamos citar os mais conhecidos, como Saviani (1986 e 1984), Kuenzer (1998 a, 1989, 2004), Frigotto (2001a, 2011b, 2002), Franco (1989), Machado (1989), Nosella (1989), Ferreti e Madeira (1992). No espectro mundial, seguindo uma tradição entre os marxistas, provalmente Gramsci tenha sido o pensador que mais debateu o tema, sem contar, é claro, Makarenko (1985) e também Pistrak (1981). Manacorda (1997), por sua vez, procura dissecar o assunto em Gramsci e Enguita (1993) (TUMOLO, 2005, p.240).
} 


\section{Pressupostos teóricos e históricos da relação Trabalho - Educação}

A fim de ampliar nossa análise, apresentamos a ideia de Marx e Engels sobre a educação politécnica e tecnológica, como proposta de integrar o trabalho produtivo ao escolar:

[...] Por educação entendemos três coisas: Educação intelectual. Educação corporal, tal como a que se consegue com os exercícios de ginástica e militares. Educação tecnológica, que recolhe os princípios gerais e de caráter cientifico de todo o processo de produção e, ao mesmo tempo, inicia as crianças e os adolescentes no manejo de ferramentas elementares dos diversos ramos industriais (MARX; ENGELS, 1992, p.60).

É necessário compreender esse debate teórico elaborado por Marx, no sentido amplo de educação politécnica, para uma formação geral que vincule a relação entre educação e prática social e o trabalho como princípio educativo. Também cabe destacar que esse pensamento abrange toda a educação básica, desde a educação infantil até o ensino médio, mas neste texto enfatiza-se o Ensino Médio de Jovens e Adultos.

O trabalho como princípio educativo leva-nos, a partir deste fundamento, a discuti-lo como elemento constitutivo do próprio ser humano. Tal discussão sustentase em Engels (2004, p. 13), em que o trabalho é a "condição básica e fundamental de toda a vida humana", ao mesmo tempo em que o "trabalho criou o próprio homem". Sendo assim, a natureza do homem é o trabalho, sua ontologia ${ }^{6}$.

É pelo processo do trabalho que o ser humano produz sua essência, sua funcionalidade social e sua história. Nesse sentido, o trabalho no processo histórico integra profundamente a relação homem e natureza, sendo indispensável para sua sobrevivência, enquanto atividade e valor de uso. "Antes de tudo, o trabalho é um processo entre o homem e a natureza, um processo em que o homem, por sua própria ação, media, regula e controla seu metabolismo com a natureza" (MARX, 2004, p. 36).

A relação do homem com a natureza está relacionada à sua apropriação e transformação dessa natureza em objeto para sua subsistência, em meios de criação ou local de utilização como processo de trabalho:

\footnotetext{
${ }^{6}$ A termologia foi aprofundada por Lukács, na escrita: "Para a ontologia do ser social o trabalho". Tradução do Prof. Ivo Tonet (UFAL), a partir do texto II Lavoro, primeiro capítulo do segundo tomo de Per uma Ontologia dell' Essere Sociale. Roma: Editori Riuniti, 1981.
} 
No processo de trabalho a atividade do homem efetua, portanto, mediante 0 meio de trabalho, uma transformação do objeto, pretendida desde 0 princípio. O produto extingue-se no produto. Seu produto é um valor de uso; uma matéria natural adaptada às necessidades humanas mediante transformação da forma (MARX, 2004, p. 40-41).

Nesse momento, percebe-se o processo de trabalho como reprodução social, o que vem marcando o desenvolvimento da sociedade, e diferenciando os homens dos animais, pela objetivação do pensamento, resulta no próprio trabalho. Posteriormente, encontra-se o processo de valorização que tem estreitado sua dimensão, representando a forma histórica do modo de produção do capital. Marx (2004, p. 67) apresenta

Como unidade do processo de trabalho e processo de formação de valor, o processo de produção é processo de produção de mercadorias; como unidade de processo de produção capitalista, forma capitalista da produção de mercadorias.

Com a diferenciação do trabalho social da apropriação do trabalho, em que entram em cena as questões de salário, preço e lucro, que são a base do sistema capitalista, a força de trabalho torna-se uma mercadoria. Para Marx (2004, p.92):

Esse tipo de troca entre capital e o trabalho é que serve de base à produção capitalista, ou ao sistema de trabalho assalariado e tem de conduzir, sem cessar, a constante reprodução do operário como operário e do capitalista como capitalista.

Diante disso, infere-se que quanto mais o trabalho produz, mais geração de mais valia e capital para os capitalistas, tende-se a um distanciamento do objeto e da função social do trabalho transformando-o em ação coisificada e alienada. Essas relações de produção e de alienação do trabalho que estabelecem a sociedade capitalista, quanto mais o trabalhador produz, mais se priva dos meios de vida. Isto ocorre porque primeiro o mundo exterior sensível deixa de ser objeto pertencente ao seu trabalho e segundo porque deixa de ser o meio direto de sua subsistência (MARX, 2004, p. 178). A partir dessa relação de estranhamento, desenvolve-se a propriedade privada, acumulação de riquezas daquele que compra a força de trabalho, pois a força de trabalho, como mercadoria, passa a ser propriedade daquele que paga pela produção de outras mercadorias.

Esse modo de produção que trata o trabalho como mercadoria marca os diversos e contraditórios regimes de acumulação e o próprio desenvolvimento do 
capitalismo. Nesse sentido, cabe destacar a necessidade de se reafirmar a centralidade do trabalho, ainda que, para muitos críticos, a contemporaneidade seja caracterizada pelo fim de sua centralidade ${ }^{7}$. 0 trabalho assalariado, como emprego da mercadoria "força de trabalho" faz do ser humano mera peça na cadeia produtiva do capitalismo.

Entretanto, dado a concepção do trabalho como a práxis humana, de desenvolver as condições necessárias à existência como produção histórica e das relações sociais, é impossível negar a centralidade do trabalho, mesmo com a premissa de outro sistema que não seja o capitalismo, ou que as transformações sociais exigem menos força de trabalho humano. Tais argumentos são findáveis, de acordo com Antunes (2005, p. 39):

[...] em vez da substituição do trabalho pela ciência, ou ainda da substituição da produção de valores de troca pela esfera comunicacional ou simbólica, da substituição da produção pela informação, o que vem ocorrendo no mundo contemporâneo é uma maior inter-relação, maior interpenetração entre as atividades produtivas e as improdutivas, entre as atividades fabris e de serviços, entre atividades laborativas e as atividades de concepção, entre produção e conhecimento científico, que se expandem fortemente no mundo contemporâneo.

Diante das transformações do trabalho e sua organização, a reconfiguração do capitalismo exige uma nova relação com a produção do conhecimento, demandando uma nova formação oferecida aos estudantes nas instituições escolares. Enfim, constitui-se em um projeto educacional que acompanha o desenvolvimento de uma sociedade estruturada nas formas contemporâneas do modo de produção capitalista.

Com exigências que marcam a imposição e expansão do capital, a reestruturação produtiva vem apontando para uma produção mais aligeirada, com

\footnotetext{
${ }_{7}$ Mesmo com a globalização e introdução de novas tecnologias, que pode representar acentuada redução do valor de uso da força de trabalho, refletir em as altas taxas de desemprego, o fim da centralidade do trabalho implicaria no extermínio da mercadoria força de trabalho o que, por sua vez, seria o fim do capitalismo. Dessa forma, entendemos que as dinâmicas das relações sociais de produção podem levar a um maior desemprego e o incentivo para uma formação mais intelectual e complexa. Mesmo assim, esse movimento não poderá negar a categoria trabalho, discutida por Engels, Marx e Lukács como fundamento do ser social e do processo de valorização e alienação, embora isso seja defendido por alguns autores como Viera e Ouriques (2006, p.155), em seu texto "Elementos para uma crítica da centralidade do trabalho", onde defendem o movimento do Neolafarguismo, que propõe que os trabalhadores se libertem do jugo do trabalho, no qual a vida deixe de girar em torno do trabalho e de acumulação de riqueza, sendo essa uma invenção do capitalismo. Entendemos que para romper com o capitalismo é superar a exploração da força de trabalho, o que não significa o fim da centralidade do trabalho.
} 
menor custo salarial. Com tais desafios as bases taylorista/fordista, centradas no tecnicismo e de ações mecanizadas, que deram origem ao ciclo das economias capitalistas, entram em crise, e se veem aos poucos sendo substituídas pelo regime de acumulação flexível (HARVEY, 1998). Tais mudanças influem na divisão social e técnica de trabalho e, consequentemente, alteram as relações entre trabalho e educação, pois o regime de acumulação flexível exige um trabalhador polivalente, demandando, por sua vez, educação polivalente, que promova articulação das experiências e atitudes, competências, habilidades, flexibilização e adaptação aos diferentes contextos do trabalho produtivo.

Cabe-se ressaltar que existem contradições como trabalho produtivo, servindo à degradação do próprio homem, na qual demandas da acumulação capitalista se apropriam da força de trabalho melhor qualificada dentro dos moldes do desenvolvimento econômico, industrial e tecnológico. Configura-se também maior exigência de escolarização para ocupar os novos postos de trabalho e pela promessa da empregabilidade, como uma responsabilidade individual.

Para Tumolo (2005, p. 256), "o trabalho só poderia ser princípio balizador de uma proposta de educação que tenha uma perspectiva de emancipação humana numa sociedade baseada na propriedade social". O entendimento de trabalho como princípio educativo é mais do que apropriação pela classe trabalhadora de conhecimentos científicos, tecnológicos e sócio-históricos. Faz-se necessário compreender as contradições entre capital e trabalho, que envolvem a percepção das relações de trabalho vivenciadas na sociedade capitalista e as diferenças do estar empregado e a natureza do trabalho que constituem o próprio homem.

Seguindo a esteira da discussão do trabalho como princípio educativo, Frigotto, Ciavatta e Ramos (2005. p. 2) argumentam que:

O trabalho como princípio educativo vincula-se, então, à própria forma de ser dos seres humanos. Somos parte da natureza e dependemos dela para reproduzir a nossa vida. E é pela ação vital do trabalho que os seres humanos transformam a natureza em meios de vida. Se essa é uma condição imperativa, socializar o princípio do trabalho como produtor de valores de uso, para manter e reproduzir a vida, é crucial e "educativo". [...] É dentro desta perspectiva que Marx sinaliza a dimensão educativa do trabalho, mesmo quando o trabalho se dá sob a negatividade das relações de classe existentes no capitalismo. A própria forma de trabalho capitalista não é natural, mas produzida pelos seres humanos. A luta histórica é para superála. 
A constituição de um projeto educativo que valorize a formação do trabalhador é um espaço de luta hegemônica do capital, no qual muitos trabalhadores ficam desigualmente incluídos no sistema. É imprescindível romper com essa barreira desumanizadora do trabalho, criando condições para educar na perspectiva emancipatória, objetivando o papel da escola pela formação integral nas proposições da conscientização, da criticidade e dos conhecimentos científicos, sociais e culturais que valorizem o ser e o fazer humano. Como menciona Franco:

[...] Com isso, estaria dando a sua contribuição para que o futuro trabalhador tivesse acesso às novas contribuições da ciência e da técnica que, por sua vez, deverão ser revolucionadas pelo coletivo dos trabalhadores (FRANCO, 1988, p. 86).

Com base nas contribuições de Franco (1988), reitera-se o papel da escola que sustente uma concepção de educação baseada nas relações histórico-sociais como o aporte para a construção, ressignificação e consolidação de conhecimentos ao serem considerados os saberes constituintes dos sujeitos participantes nos processos formativos de ensino e aprendizagem. Em resposta ao princípio educativo específico do ensino médio, seja ele integrado ou profissionalizante, não deve ser pautado na preparação para o mercado, mas no método de estudo, pesquisa e contradições da sociedade pelo próprio trabalho que constitui o ser humano, sobretudo para o Ensino Médio de Educação de Jovens e Adultos, o qual não pode ser mencionado sem estar articulada ao trabalho, que exige o pensar na sociedade na sua complexidade e totalidade:

Se não se pode ignorar a importância da educação como pressuposto para enfrentar o mundo do trabalho, não se pode reduzir o direito à educação - subjetivo e inalienável - à instrumentalidade da formação para o trabalho com um sentido economicista e fetichizado. É, portanto, um desafio para a política de Educação de Jovens e Adultos (EJA) reconhecer o trabalho como princípio educativo, primeiro por sua característica ontológica e, a partir disto, na sua especificidade histórica, o que inclui o enfrentamento das instabilidades do mundo contemporâneo (FRIGOTTO, CIAVATTA, RAMOS, 2005, p. 15).

$\mathrm{Na}$ base da compreensão sobre a importância do Ensino Médio, considerada a última etapa da Educação Básica, a qual deve ser estendida à Educação de Jovens e Adultos, possui em sua gênese o trabalho como princípio educativo. Isso 
implica que, assumir o conceito de Politecnia enquanto a junção entre educação e trabalho, no sentido ontológico, proporciona uma formação que articule o estudo e o aprendizado da ciência, da tecnologia, da vida, da política, da história, da sociedade e das transformações no mundo do trabalho. Há, ainda, outro aspecto a considerar sobre as relações entre trabalho e educação, isto é, a compreensão do que vem sendo produzido historicamente como políticas educacionais no ensino médio, em especial, na modalidade de jovens e adultos.

\section{Ensino Médio de Jovens e Adultos: perspectiva histórica e trabalho como princípio educativo}

Diante das discussões sobre a relação de trabalho e educação é que, nesse momento, procura-se compreender historicamente a trajetória do Ensino Médio na Educação de Jovens e Adultos, a partir dos escritos de Frigotto, Ciavatta e Ramos (2005), Haddad (1987, 2000, 2007), Di Pierro (1992, 2000, 2001, 2005), Barreto (2005), MEC (2009) e Nosella (2011), para analisar a possibilidade do trabalho como princípio pedagógico.

As primeiras ações educativas envolvendo adultos se configuram no Período Colonial, realizada pelos jesuítas, que alfabetizavam o povo como forma de catequização e doutrinação nas perspectivas religiosas do catolicismo, sendo compreendida nos aspectos da educação formal. Segundo Haddad e Pierro (2000), no período imperial encontramos informações sobre ações educativas a partir dos direitos legais, sendo a primeira "garantia de uma instrução primária e gratuita para todos os cidadãos" (p.109). Assegurada pela primeira Constituição Federal de 1824, esta que priorizava mais especificamente as crianças, ocasionando na época um crescente índice de analfabetos, no entanto, essa garantia foi concebida somente no aparato jurídico.

Durante a Primeira República, a Constituição Federal de 1891 delega a responsabilidade do Ensino Básico para os estados e municípios. Porém, na prática, esta não se efetiva, por falta de investimentos para garantir as propostas legais. Os dados do Censo de 1920 apontam que 72\% da população acima de cinco anos permaneceu analfabeta e excluída do voto pela mesma constituição (BARRETO, 2005 , p. 44). Cabe analisar que nesse momento se configura uma educação escolarizada voltada para as elites em detrimento das camadas populares, onde a 
legislação, que garante uma escola para todos, avança lentamente, não passando da intenção legal.

Com o fim da Primeira Guerra Mundial e, posteriormente, a Revolução de 30, os altos índices de analfabetismo tornam-se uma preocupação social, política e econômica. Presente nesse contexto a dualidade do ensino médio (secundário) no Brasil, com o advento da industrialização, já era organizado um ensino com duas vertentes: um ensino secundário regular voltado para a elite e outro voltado para as classes trabalhadoras. Somente entrava para a universidade alunos provenientes das escolas secundárias:

A dualidade estrutural, que mantém duas redes diferenciadas de ensino ao longo da história da educação brasileira, tem suas raízes na forma como a sociedade se organiza, como expressa as relações e contradições do capital e trabalho (NASCIMENTO, 2007, p. 87)

Desde as primeiras décadas do século $\mathrm{XX}$, a educação tem operado a partir das disputas entre as classes sociais, o que tem se traduzido hegemonicamente na formação de força de trabalho para atender à exigência do modelo industrial em expansão, suprindo as necessidades de produção de cada momento histórico. Com o desdobramento da Constituição de 1937, a Lei Orgânica do Ensino Secundário de 1941, a "Reforma Capanema" apresenta o ensino profissional passado para o nível médio, as escolas industriais dependiam de exames de admissão e os cursos foram divididos em dois níveis tendo dois ciclos, um básico e outro técnico industrial.

No mesmo período, surge o Instituto Nacional de Estudos Pedagógicos (INEP), criado em 1938, que no âmbito de suas pesquisas institui o Fundo Nacional de Ensino Primário e destina 25\% de recursos financeiros para o ensino supletivo de jovens e adultos analfabetos. Demonstra-se, então, uma preocupação mais significativa na extensão da Educação de Jovens e Adultos, área que começa a se afirmar no campo das políticas nacionais. Essas iniciativas são decorrentes do processo contraditório do sistema capitalista e da aceleração da urbanização no Brasil, após a Segunda Guerra Mundial. Não se pode desconsiderar ainda, a influência da Organização das Nações Unidas, que em novembro de 1945, declara a importância da educação, em especial, a educação de adultos, para o desenvolvimento capitalista dos países. Assim é que nessa conjuntura política o empreendimento dos esforços para diminuição dos índices elevados do 
analfabetismo, das promoções de ações educativas e da expansão do ensino emerge no intuito da redefinição do Estado no âmbito mundial.

Com a primeira Lei de Diretrizes e Bases da Educação Nacional, n. 4.024, em 1961, foi possível aos diplomados das escolas técnicas o ingresso no ensino superior, através de um projeto que passou despercebido pela Câmara, habilitando os diplomados dos cursos técnicos ao ingresso no ensino superior (NOSELLA, 2011, p. 1054).

Posteriormente, com a formulação da Lei n. 5.692/1971 que redefine as Diretrizes e Bases da Educação Nacional, regulamenta-se a formação de técnicos em regime de urgência a fim de atender o acelerado processo de expansão industrial e infraestrutura brasileira. Com a reforma educacional dos governos militares, a Lei n. 5692/1971 propôs uma escola média única para todos com três anos de ensino médio ( $2^{\circ}$ grau) para os jovens de 15 a 17 anos, com profissionalização obrigatória. Ocorria, então, a integração verticalizada do ensino profissional com o secundário.

A Lei n. 5.692/71, com o intuito de universalizar uma escola de técnicos submissos, de operadores práticos, fracassa, havendo o corte da parte humanística e crítica do currículo assim como o esvaziamento do ensino técnico. Também garante o ensino supletivo, que pela primeira vez, sistematiza o acesso de jovens e adultos ao ensino público em capítulo especial, pode-se considerar como uma primeira conquista no campo dos direitos da escolarização de jovens e adultos; contudo cabe ressaltar, que essa legislação concebia o ensino como suplência da escolarização regular e com complementação de cursos de aprendizagem (1º grau) e qualificação profissional ( $2^{\circ}$ grau).

Tais providências, legitimadas pela hegemonia da Teoria do Capital Humano (SCHULTZ, 1971), que postula o investimento em educação como variável para o aumento da produtividade e, por conseguinte, ascensão social, se configura, mais uma vez, para atender a necessidade de formação de mão de obra das indústrias em desenvolvimento e manutenção no sistema capitalista, o qual identifica a educação como prioridade para acompanhar ao modelo global de sociedade.

Em 1980 o governo militar foi pressionado pela população para expansão da escola pública, em resposta ofereceu cursos noturnos e supletivos. Em seguida, em 1982, pela Lei n. 7.044/1982, determina-se que a profissionalização não mais fosse 
obrigatória, mas opcional de cada escola. A partir da criação da Constituição Federal de 1988, que assegura a educação como direito de todos e dever do Estado, emerge a terceira Lei Federal n. 9.394, de 20 de dezembro de 1996 - Lei de Diretrizes e Bases da Educação Nacional (LDBEN), que apresenta inovações principalmente na seção que se destina a jovens e adultos.

$\mathrm{Na}$ nova legislação, o ensino supletivo passa por uma reconceituação, sendo entendido como Educação de Jovens e Adultos, integrante da Educação Básica (Ensino Fundamental e Ensino Médio) a ser oferecido gratuitamente e que pode acontecer por meio de cursos ou exames supletivos. Outra mudança é o rebaixamento das idades sendo de 15 anos para o Ensino Fundamental e 18 anos para o Ensino Médio. A EJA, modalidade da Educação Básica, é direito subjetivo garantido para "aqueles que não tiveram acesso ou continuidade de estudos nos ensinos fundamental e médio na idade própria e constituirá instrumento para a educação e a aprendizagem ao longo da vida" (BRASIL, 1996, Art. 37).

Nessa nova configuração política de redemocratização do país, também temos em pauta a volta da discussão polarizada: de um lado os neoliberais (meritocracia, identidade própria do ensino médio, retirando disciplinas de formação geral) e do outro lado os defensores do modelo de educação politécnica, organizados pelos sujeitos sociais forjados em movimento pelo fortalecimento da escola/educação pública.

Cabe ressaltar que a LDBEN de 1996 expressa uma conciliação entre as forças progressistas em defesa da educação pública e gratuita e, de outro lado, as alianças constituídas pelas forças neoliberais que visam o vasto mercado educacional; também, as neoconservadoras - contrárias à laicidade da educação e preservação da moralidade cristã.

No ano de 1997, com Decreto n. 2.208/1997, o grupo político hegemônico do governo neoliberal do então presidente da república Fernando Henrique Cardoso aprovou a divisão entre ensino médio regular e técnico, liberando o ensino técnico de qualquer controle burocrático. Com a mudança de governo em 2003 é regulamentado o decreto n. 2.208/1997 propiciando mudanças que se conservam, e criando o Decreto n. 5.154 de 2004 como política de integração entre a educação básica e a educação profissional, sendo oferecida a educação profissional e técnica simultaneamente ao longo do ensino médio em caráter opcional. 
No quadro da política educacional brasileira pós anos 2000, é fundamental destacar a consolidação das formas como que o empresariado vai passando a influenciar os rumos da educação em todos os níveis, etapas e modalidades. A constituição do movimento "Todos pela Educação" aglutinando diversas organizações empresariais é um marco na reorientação da política educacional no país, a qual passa ser induzida pelos interesses deste movimento desde as estruturas dos governos. Se antes os empresários influenciavam pontualmente na educação e escola pública, sua ação, pós 2003, afetará toda política educacional. Por isso, é possível dizer, conforme a interpretação de Leher (2014) que todas as políticas desenvolvidas no âmbito educacional têm relação com os interesses dos empresários organizados no "Todos pela Educação", principalmente após a instituição do Plano de Desenvolvimento da Educação - PDE.

Neste sentido, o decreto n. 5.840 de 2006 institui o Programa de Integração da Educação Profissional com a Educação de Jovens e Adultos- PROEJA. Assim, pela primeira vez, aparece especificamente o ensino fundamental, médio e a educação indígena integrados ao profissional voltado para a Educação de Jovens e Adultos, possibilitando o direito à formação mínima. As palavras recorrentes são: integração, articulação, interdisciplinaridade e inovação. Os eixos orientadores do ensino médio devem ser: trabalho, ciência, tecnologia e cultura. Dessa forma, possui outro programa profissionalizante, a Escola de Fábrica (com políticas compensatórias de viés assistencialistas e o PROJOVEM- inserção profissional), mas que, infelizmente possui um caráter de política curricular com ênfase no individualismo e na formação por competências designadas estritamente para 0 mercado de trabalho ${ }^{8}$.

Outras políticas ratificam a materialidade de nosso argumento: o Exame Nacional do Ensino Médio - ENEM - deixou de ser um simples instrumento de avaliação desse nível, para tornar-se a principal porta de acesso para a universidade pública brasileira, bem como instituições privadas (por meio do Programa

\footnotetext{
${ }^{8}$ Além destas pode-se destacar algumas ações que buscaram estabelecer a reforma do Ensino Médio. Como o Ensino Médio Inovador proposto pelo Ministério da Educação (MEC), integrado as ações do Plano de Desenvolvimento da Educação - PDE. Essa proposta do MEC tem cinco questões centrais a serem discutidas no currículo do ensino médio. A primeira é estudar a mudança da carga horária mínima do ensino médio para três mil horas - um aumento de 200 horas a cada ano. Outra mudança é oferecer ao aluno a possibilidade de escolher $20 \%$ de sua carga horária e grade curricular, dentro das atividades oferecidas pela escola. Faz parte ainda da proposta, associar teoria e prática, com grande ênfase a atividades práticas e experimentais, como aulas práticas, laboratórios e oficinas, em todos os campos do saber; valorizar a leitura em todas as áreas do conhecimento; e garantir formação cultural ao aluno.
} 
Universidade para Todos - PROUNI). Além disso, até 2016, o ENEM assumiu o caráter supletivo, sendo retomado pelo Exame Nacional de Certificações e Competências e Habilidades de Jovens e Adultos (ENCCEJA) ${ }^{9}$, uma vez que qualquer pessoa com o Ensino Fundamental completo, ao prestar o exame e ser aprovado, teria concluído o nível médio sem a necessidade de assistir uma aula sequer. Caso, ainda, o estudante tenha atingido a média para algum curso em nível superior, ele poderá matricular-se na universidade e iniciar a graduação.

Atualmente, a certificação de jovens e adultos, por exames nacionais, é oferecida para conclusão do Ensino Fundamental e do Ensino Médio pelo ENCCEJA. Segundo a Resolução do Conselho Estadual de Educação (CEED/RS) $n$. 313, de 16 de março de 2011, que estabelece orientações à oferta da Educação de Jovens e Adultos - EJA, no Sistema Estadual de Ensino do Rio Grande do Sul, argumenta que os exames supletivos ofertados a nível nacional avaliam habilidades e competências das áreas do conhecimento, especialmente as de leitura, interpretação e elaboração textual, e capacidade de resolução de problemas, por meio de questões interdisciplinares contextualizadas. As orientações curriculares do documento devem ser readequadas não só aos programas preparatórios para os exames, mas também as propostas pedagógicas dos cursos de EJA, tanto presenciais como a distância.

As orientações sustentadas pela Resolução justificam-se, segundo o documento, pela possibilidade de contribuírem na contextualização curricular da modalidade de EJA. Destaca-se, ainda, a necessidade da organização do currículo por áreas do conhecimento, com o planejamento integrado dos professores de cada uma das disciplinas das áreas numa visão interdisciplinar.

A reestruturação do Ensino Médio $^{10}$, também, procurou levantar o debate sobre a problemática encontrada por esse nível, sobretudo num período em que se

\footnotetext{
${ }^{9}$ Conforme estabelecido pela Portaria Ministerial n. 2.270, de 14 de agosto de 2002, no governo de Fernando Henrique Cardoso, foi criado o ENCCEJA. Uma política de oferta rápida de certificação do Ensino Fundamental e Médio a jovens e adultos que também almejavam a avaliação e a comprovação da conclusão dos níveis de ensino da Educação Básica. Segundo o site do portal do Ministério da Educação (MEC24), o ENCCEJA foi apresentado como proposta do MEC ao INEP com os seguintes objetivos: avaliar as habilidades e competências básicas da EJA e assim construir uma referência nacional de EJA, que compreenda as competências, habilidades e saberes adquiridos na educação formal ou dentre os diversos contextos que possibilitam a constituição de aprendizagens, como a família, as relações sociais, o trabalho, a religião, a participação em sindicatos e movimentos sociais, entre outros. Todos estes conhecimentos procuram estar presente nas questões de múltipla escolha.

${ }^{10}$ Reestruturação e Expansão do Ensino Médio no Brasil (GT Interministerial instituído pela Portaria n. 1189 de 05 de dezembro de 2007 e a Portaria n. 386 de 25 de março de 2008).
} 
iniciavam as formulações do texto para o Plano Nacional de Educação (PNE) (2014 - 2024). Motivada pela quase estagnação do índice de matrículas ocorridas nesse nível na primeira década do século $X X^{11}$, a proposta para a reestruturação do ensino médio, grosso modo, buscou:

A melhoria da qualidade do ensino médio nas escolas públicas estaduais, promovendo, ainda, os seguintes impactos e transformações: superação das desigualdades de oportunidades educacionais; universalização do acesso e permanência dos adolescentes de 15 a 17 anos no ensino médio; consolidação da identidade desta etapa educacional, considerando a diversidade de sujeitos; oferta de aprendizagem significativa para jovens e adultos, reconhecimento e priorização da interlocução com as culturas juvenis (BRASIL, 2009, p. 5).

Articulado a essa política, foi lançado, no final do ano de 2013, o Pacto Nacional para Fortalecimento do Ensino Médio no Brasil. O pacto, ainda com pouco tempo de vida, é uma política proposta pelo governo federal e de livre adesão das secretarias estaduais de educação, cujo objetivo é, entre outros, capacitar as práticas dos professores para a implantação das Diretrizes Nacionais do Ensino Médio - DCNEM (2012). Além de oferecer assessorias locais, a política propõe uma verdadeira reestruturação do Ensino Médio, a aqueles estados que aderirem. O Pacto de Fortalecimento do Ensino Médio ofereceu a única possibilidade de formação que se aproximava da organização curricular assumida pelo Ensino Médio Politécnico no RS.

Nesse contexto, o trânsito para a aprovação do PNE em paralelo ao PDE expõe questões de superfície e fundo sobre o tema. Após amplos debates nas conferências municipais, estaduais e nacional, o Plano Nacional é a síntese democrática das orientações construídas por entidades representativas dos estudantes, pais, professores e comunidade que, durante dois anos definiram os rumos da educação para o decênio (2011-2020). Entretanto, este plano permaneceu até 2014 em debate, pois não havia consenso, principalmente sobre o valor da porcentagem do Produto Interno Bruto (PIB) que seria destinado à educação e se esse recurso seria direcionado às instituições públicas ou à educação de modo

\footnotetext{
${ }_{11}$ Segundo Kuenzer (2010), "se as matrículas no ensino médio cresceram 32,1\% entre 1996 e 2001, passando de aproximadamente 5,7 milhões para 8,4 milhões, no quinquênio seguinte cresceram apenas $5,6 \%$, passando a decrescer a partir de 2007, de modo a configurar crescimento negativo de $8,4 \%$ de 2000 a 2008, segundo os dados do INEP. Esta retração se acentua entre 2008 e 2009, atingindo um percentual de $-3,2 \%$, sendo que, em 2008, foram 8.369.389 matrículas contra 8.337.160 em 2009; ou seja, em apenas um ano, uma diferença de 32.229 matrículas" (p. 859).
} 
geral, incluindo, inclusive, estabelecimentos privados e comunitários. Apesar das modificações e da lógica que permeia a construção do documento (alcance de metas), o plano foi aprovado para o período (2014-2024).

No início do ano de 2017, foi instituída a Lei n. 13.415, de 16 de fevereiro de 2017, como sendo a lei que estabelece a Reforma do "Novo Ensino Médio", proposto no Governo Temer e pelo MEC. A legislação do Novo Ensino Médio teve origem na Medida Provisória n. 746, de 22 de setembro de 2016. A lei, medida provisória, trata das alterações na LDBEN/1996 com relação à organização curricular e a instituição da Política de Fomento à Implementação de Escolas de Ensino Médio em Tempo Integral. Cabe ressaltar que a implementação da reforma depende da homologação da Base Nacional Comum Curricular (BNCC), documento que visa orientar o currículo em âmbito nacional, iniciado em 2015, o texto final referente à Educação Infantil e Ensino Fundamental foi homologado no dia 20 de dezembro de 2017 pelo presidente Michel Temer e pelo Ministro da Educação Mendonça Filho, e a parte do documento que trata do Ensino Médio foi entregue em abril de 2018 para análise no Conselho Nacional de Educação (CNE) em virtude das discussões sobre Reforma do Ensino Médio. A proposta do Novo Ensino Médio ${ }^{12}$ centra-se em três questões no âmbito de uma Reforma Curricular: Ensino Integral, Estrutura Curricular e Formação Técnica.

Com relação ao Ensino Integral está proposto a sua implementação de forma gradual, aumentando sua carga horária de 800 horas em 200 dias letivos para 1400 horas, sendo que em cinco anos deve chegar, pelo menos, à oferta de 1000 horas. A ampliação para ensino em tempo integral conta com a instituição da Política de Fomento à Implementação de Escolas de Ensino Médio em Tempo Integral que prevê o repasse de recursos financeiros do MEC durante o período de 10 anos para os Estados e o Distrito Federal, conforme acordo entre a União e os Estados.

No que se refere à estruturação curricular do Novo Ensino Médio está proposta a organização entre os conteúdos definidos pela BNCC e os itinerários formativos escolhidos pelo estudante. A obrigatoriedade da BNCC, com as áreas de conhecimento, segue o modelo proposto pelo ENEM (linguagens e suas tecnologias, matemática e suas tecnologias, ciências da natureza e suas tecnologias e ciências humanas e sociais aplicadas que incluem arte, filosofia, sociologia e educação

12 Disponível em: http://portal.mec.gov.br/component/content/article?id=40361 
física), não pode ser superior a 1800 horas nos três anos do Ensino Médio. O itinerário formativo escolhido pelo estudante é composto por ênfase em uma área de formação que pode ser em linguagens, matemática, ciências da natureza, ciências humanas e formação técnica e profissional. $O$ ensino de português e matemática são obrigatórios durante os três anos do ensino médio. E com relação à Língua estrangeira tem-se a obrigatoriedade do ensino de Língua Inglesa e oferta de outras línguas estrangeiras de maneira facultativa.

A formação técnica e profissional, caso escolhida pelo estudante, poderá ser ofertada em parceria com outras instituições. Os professores da formação técnica poderão ser profissionais de notório saber em sua área de atuação ou com experiência profissional atestados por titulação específica ou prática de ensino, para ministrar conteúdos de áreas afins à sua formação ou experiência profissional, para atender à demanda da formação técnica e profissional no ensino médio, sem necessidade de formação pedagógica. Essa nova legislação prevê que essa formação ocorra inclusa na carga horária do ensino médio e, ao final, o estudante obterá o diploma do ensino médio regular e um certificado do ensino técnico.

A apresentação das políticas educacionais dirigidas ao Ensino Médio no Brasil possibilita o exame de alguns modos pelos quais vêm sendo produzido o currículo no Ensino Médio. Neste sentido, indaga-se sobre os sentidos que podem adquirir a proposição de uma relação entre trabalho e educação como princípio educativo para o ensino médio na modalidade EJA, tendo como escopo específico os cenários de disputa e tensões vivenciados no processo histórico do ensino médio.

Sobre o Ensino Médio, desafios permanecem. Para Kuenzer (2010):

Definir metas e indicadores claros para esta etapa, as responsabilidades pela sua execução e as formas de acompanhamento e controle que deverão ser realizadas no período de implementação do Plano, prevendo fóruns específicos periódicos, pelo menos a cada três anos, para revisão de rumos a partir de dados que explicitem claramente os percentuais atingidos em relação ao proposto para o decênio (KUENZER 2010, p. 857).

O desenvolvimento histórico do Ensino Médio brasileiro demonstra a sua relação com as demandas apresentadas pela sociedade capitalista que, por sua vez, estão inter-relacionadas com o movimento macroeconômico nacional e internacional que no Brasil, manifesta-se, desde sempre, pelas relações de dependência e a combinação de interesses da burguesia interna e externa (FERNANDES, 2009). 
Nesse último período, quando presenciado o avanço do empresariado nas políticas públicas para o Ensino Médio, presencia-se que tais políticas buscam capacitar a juventude para adaptação à empregabilidade, denominando tal postura por "democratização do acesso" (Rummert; Algebaile; Ventura, 2013, p. 723). É inegável que houve avanços importantes, sobretudo pela criação de novas escolas, o que permitiu que mais pessoas ascendessem ao nível médio de ensino. Porém, a ampliação de vagas e escolas de Ensino Médio, em última instância, tem atendido a quais interesses? Quer, de fato, o Ensino Médio oferecer ferramentas aos jovens brasileiros para que somem esforços nas lutas da classe trabalhadora, sendo eles filhos dessa classe? Rummert, Algebaile e Ventura (2013) sintetizam os limites dessas políticas, justamente pela forma pulverizada como se apresentam:

\begin{abstract}
Associando-se o paradigma econômico - definido pela posição do Brasil na condição de integração subalterna no capital-imperialismo, à demanda social, em parte gerada pela difusão midiática das teses do capital humano, é criada uma miríade de ofertas de elevação de escolaridade/formação profissional/certificação. A multiplicidade, desordenada, flácida e de difícil acompanhamento e controle, mergulha a totalidade social na fantasia de que a efetiva democracia chegou à educação escolar, como se fosse factível construí-la pelo alto e tão somente no âmbito educacional (RUMMERT; ALGEBAILE; VENTURA 2013, p.724).
\end{abstract}

A história tem demonstrado que um projeto de sociedade com base em um consentimento social passivo, sem resistências ativas, é fruto, dentre outras práticas, de uma construção ideológica das classes dominantes, as quais se manifestam nas políticas educacionais destinadas à classe trabalhadora. Segundo Rummert (2014, p. 75), essas políticas contribuem como "uma forte polivalência funcional ao permanente processo de construção e manutenção de hegemonia". Na medida em que o Ensino Médio brasileiro incorpora em suas orientações políticas e curriculares os objetivos de formação flexível, onde a finalidade é a constituição de um novo sujeito capaz de articular-se nos mais diversos ramos produtivos - portanto, em defesa da produtividade e competitividade nos limites do padrão de acumulação flexível - distancia-se de uma educação politécnica, nos termos que apresentamos ao final da primeira seção e, por isso, não oferece condições para a superação da dualidade histórica que marca esse nível de ensino.

Por isso, o Ensino Médio permanece um campo de disputas, as quais refletem nas políticas educacionais, assimetricamente, a dualidade histórica entre os 
interesses da burguesia e dos trabalhadores, expressão aparente da contradição estrutural entre Trabalho e Capital, ainda que haja um esforço ideológico para subsumir tal contradição. Atualmente tal contradição não passa indiferente às políticas educacionais diante da reforma do Ensino Médio com a promulgação da Lei n. 13.415/2017 e aprovação em dezembro de 2018 da parte destinada ao Ensino Médio na BNCC em que a proposta está centrada em competências que visam definir 'direitos e objetivos de aprendizagem do ensino médio', conforme expresso na legislação e no documento da base. As atuais reformas passam a controlar os conhecimentos como modo de atender as transformações do mercado de trabalho na perspectiva da flexibilidade de empreendedorismo, características necessárias exigidas ao trabalhado que se afasta da discussão de mundo de trabalho e nega o conhecimento construído historicamente para os jovens e adultos do Ensino Médio.

Percebe-se que, em se tratando das políticas educacionais para a EJA, colocam a ênfase na defesa de uma discussão curricular de formação para o mundo do trabalho. Em relação a essa discussão, Soares (2001) destaca a importância de se discutir as políticas educacionais de EJA, considerando que muitas vezes são reduzidas à dimensão do mercado de trabalho, sendo necessário superar esse pragmatismo de preparação para o trabalho e avançar na concepção mais ampla do processo de escolarização, compreendendo as dimensões humanas.

Percebe-se que, após vinte e três anos da LDBEN (1996), se mantem a ideia dessa modalidade de educação com a finalidade de integrar a participação dos jovens e adultos à vida política e produtiva, com vistas à manutenção do sistema societário vigente. Portanto, o trabalho como princípio educativo, legado do pensamento marxiano, diverge das políticas educacionais destinadas ao Ensino Médio de jovens e adultos. O "educativo" no projeto neoliberal é sinônimo de 'aprender a aprender' e de empreendedorismo.

\section{Considerações}

A presente discussão procurou compreender as relações entre trabalho $\mathrm{e}$ educação na constituição do princípio educativo do EJA. Situou-se, primeiramente, a discussão conceitual sobre os pressupostos teórico-históricos entre trabalho e educação como possibilidade de prosseguir na análise específica sobre o processo 
histórico na produção de políticas educacionais direcionadas ao Ensino Médio EJA em busca do trabalho como princípio educativo. Verifica-se, portanto, um distanciamento entre as bases conceituais da discussão de trabalho e educação do que é produzido e incorporado como discurso oficial das políticas educacionais que defendem uma formação de preparação para o mundo do trabalho.

Percebe-se, nos últimos tempos, que se prioriza a escolarização dos sujeitos pelo consequente avanço científico e tecnológico, processo esse que se por configura pressupostos constitutivos para a qualificação para o mercado em oposição ao mundo do trabalho. Sendo assim, a educação tem influências na vida das pessoas, interpelando como um elemento fundamental pela disputa de uma posição no mercado de trabalho, de melhores condições de consumo, novos e promissores cargos exigindo o investimento de formação gradual e contínua.

Esse projeto educacional de formação que vem sendo assumido na elaboração e execução de políticas públicas em educação se sustenta na lógica do desenvolvimento capitalista e da racionalidade econômica nos sistemas de ensino. Sendo um mecanismo ativo no processo de produção e de utilidade capitalista nas relações e ações, no qual o referido processo educacional constitui-se com uma nova estratégia de acumulação do capital, fundamentada no regime flexível e na formação do trabalhador polivalente e empreendedor, como estratégia de maior oferta da força de trabalho ativa no mercado e seu consequente rebaixamento em termos salariais e de direitos sociais.

Por outro lado, as formas de oferta da EJA em nível médio, as políticas educacionais para a área, seus mecanismos de certificação, formação aligeirada e diminuição do acesso aos conteúdos representativos dos conhecimentos científicos e culturais representam acentuado retrocesso em termos civilizatórios, sobretudo aos jovens que necessitam da formação para disputar uma posição social e do trabalho mais digna. Entendemos que as consequências desse modelo é a manutenção das desigualdades educacionais em nível médio, no Brasil, o que deverá refletir em uma alijada mobilidade social, principalmente pelo restrito acesso aos complexos conhecimentos exigidos pelo mundo do trabalho.

Espera-se que o debate aqui proposto se amplie e possibilite aos profissionais da educação, em especial, os que lecionam no EJA em nível médio, a compreensão 
das práticas e discursos que orientam essas políticas educacionais contemporâneas.

\section{Referências}

ANTUNES, R. A crise da sociedade do trabalho: fim da centralidade ou desconstrução do trabalho? In: O caracol e sua concha: ensaios sobre a nova morfologia do trabalho. São Paulo: Boitempo, 2005, Cap. I.

BARRETO, S. das N. O processo de alfabetização no MOVA-RS: narrativas e significados na vida de mulheres. 2005. 223f. Dissertação (Mestrado em Educação Ambiental). Instituto de Educação, FURG, Rio Grande/RS, 2005.

BRASIL. Constituição da República Federativa de 1988. 13. ed. Porto Alegre: CORAG, 2003.

Lei no 9394/1996. Institui Diretrizes e Bases da Educação Nacional. 1996. Disponível em <http://www.planalto.gov.br/ccivil_03/leis/l9394.htm> Acesso em: 05 mai 2019

$\begin{array}{cccr} & \text { Centenário da Rede Federal De Educação Profissional e } & \text { Tecnológica. } \\ \text { Brasília: } & \text { SETEC/MEC, } & \text { Disponível } & \text { em: }\end{array}$ <http://portal.mec.gov.br/setec/arquivos/centenario/historico_educacao_profissional>Ace sso em: 04 mai 2019.

Lei no 13.415, de 16 de fevereiro de 2017. Altera as Leis nos 9.394, de 20 de dezembro de 1996, que estabelece as diretrizes e bases da educação nacional, e 11.494, de 20 de junho 2007, sobre o FUNDEB, a Consolidação das Leis do Trabalho CLT, aprovada pelo Decreto-Lei no 5.452 , de 1/05/43, e o Decreto-Lei no 236, de 28/02/67; revoga a Lei no 11.161 , de 5/08/05; e institui a Política de Fomento à Implementação de Escolas de Ensino Médio em Tempo Integral. Disponível em: http://www.planalto.gov.br/ccivil_03/_ato2015-2018/2017/lei/L13415.htm. Acesso em: 04 jun.2019.

Portaria Ministerial n. 2.270, de 14 de agosto de 2002. Institui o Exame Nacional de Certificação de Competências de Jovens e Adultos - ENCCEJA. Brasília: MEC, 2002.

CONSELHO ESTADUAL DE EDUCAÇÃO - RS. Resolução 313/2011. Consolida normas relativamente à oferta da Educação de Jovens e Adultos - EJA, no Sistema Estadual de Ensino, e dá outras providências, em consonância com as diretrizes nacionais fixadas nas Resoluções CNE/CEB n‥ 3/2010 e ํ․ 7/2010.

DI PIERRO, M. C de. Educação de jovens e adultos no Brasil: questões face às políticas públicas recentes. Em Aberto, Brasília, ano 11, n. 56, out./dez. p. 22-30, 1992. 
; JOIA, O.; RIBEIRO, V. M. Visões da Educação de Jovens e Adultos no Brasil. Cadernos Cedes, ano XXI, n. 55, nov, p.58-77, 2001.

Notas sobre a redefinição da identidade e das políticas públicas de educação de jovens e adultos no Brasil. Educação e Sociedade, v.26, n.92, p.11151139, 2005.

ENGELS, F. Sobre o Papel do Trabalho na Transformação do Macaco em Homem. In: ANTUNES, R. A dialética do Trabalho: escritos de Marx e Engels. São Paulo: Expressão Popular, 2004.

FERNANDES, F. Capitalismo dependente e classes sociais na América Latina. São Paulo: Global, 2009.

FRANCO, L. A. C. Trabalho da escola. In: A escola do trabalho e o trabalho da escola. 2. ed. São Paulo: Cortez: Autores Associados, 1988.

FRIGOTO, G. CIAVATTA, M. RAMOS, M. A Política de Educação Profissional no Governo Lula: Um percurso histórico controvertido. Educação e Sociedade, Campinas, v. 26, n. 92, out, p. 1087-1113, 2005.

O trabalho como princípio educativo no projeto de educação integral de trabalhadores. In: COSTA, H. da. CONCEIÇÃO, M. Educação Integral e Sistema de Reconhecimento e certificação educacional e profissional. São Paulo: Secretaria Nacional de Formação - CUT, 2005.

GOMES, C. A. CAPANEMA, C. de F; CAMARA, J. da S; CABANELAS, L. C. Educação e trabalho: representações de professores e alunos do ensino médio. Ensaio: aval. pol. públ. Educ., Rio de Janeiro, v.14, n.50, jan./mar. p. 11-26, 2006.

HADDAD, S. A ação de governos locais na educação de jovens e adultos. Revista Brasileira de Educação, v. 12 n. 35 maio/ago. p. 197-211, 2007.

DI PIERRO, M. C. Escolarização de jovens e adultos. Revista Brasileira de Educação, n. 14, maio/ago, p. 108-130, 2000.

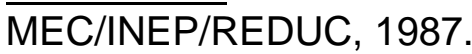

Ensino supletivo no Brasil: o estado da arte. Brasília:

HARVEY, D. Condição Pós-Moderna. 7. ed. São Paulo: Edições Loyola, 1998.

KUENZER, A. Ensino Médio no Plano Nacional de Educação 2011-2020: Superando a década perdida? Educação e Sociedade. Campinas, v.31, n.112, jul/set. p.851-873, 2010.

MARX, K. ENGELS, F. Textos sobre Educação e Ensino. 2. ed. São Paulo: Moraes, 1992.

Processo de trabalho e processo de valorização. In: ANTUNES, R. A dialética do Trabalho: escritos de Marx e Engels. São Paulo: Expressão Popular, 2004.

. Salário, preço e lucro. In: ANTUNES, R. A dialética do Trabalho: escritos de 
Marx e Engels. São Paulo: Expressão Popular, 2004.

Trabalho estranhado e propriedade privada. In: ANTUNES, R. A dialética do Trabalho: escritos de Marx e Engels. São Paulo: Expressão Popular, 2004.

MINISTÉRIO DA EDUCAÇÃO. Base Nacional Comum Curricular - Educação é a Base. Brasília, 2018. Disponível em: http://basenacionalcomum.mec.gov.br/wpcontent/uploads/2018/12/BNCC_19dez2018_site.pdf. Acesso em: 22. jan. 2019.

NASCIMENTO, M. N. M. Ensino médio no Brasil: determinações históricas. Publ. UEPG Ci. Hum., Ci. Soc. Apl., Ling., Letras e Artes, v. 15, n. 1, jun. p. 77-87, 2007.

NEVES, L. M. W. Brasil 2000: nova divisão do trabalho na educação. São Paulo: Xamã, 2000.

NOSELlA, P. Ensino Médio: em busca do Princípio Pedagógico. Educação \& Sociedade, Campinas, v. 32, n. 117, out/dez. p. 1051- 1066, 2011.

RUMMERT, S. M. ALGEBAILE, E. VENTURA, J. Educação da classe trabalhadora brasileira: expressão do desenvolvimento desigual e combinado. Revista Brasileira de Educação, Rio de Janeiro, v. 18 n. 54 jul/set., p. 717-738, 2013.

- Mundo do Trabalho e os desafios da educação dos trabalhadores urbanos. In: PALUDO, C. (Org.). Campo e Cidade em busca de caminhos comuns. Pelotas: UFPel, 2014, p. 65-76.

SAVIANI, D. História das ideias pedagógicas no Brasil. 3. ed. Campinas: Autores Associados, 2010.

SCHULTZ, T. W. O Capital Humano: Investimentos em Educação e Pesquisa. Rio de Janeiro: Zahar Editores, 1971.

SOARES, L. As políticas de EJA e as necessidades de aprendizagem dos jovens e adultos. In: RIBEIRO, V. M. (Org.). Educação de Jovens e Adultos: Novos leitores, novas leituras. Campinas, SP: Mercado das Letras, 2001, p. 201-224.

TUMOLO, P. S. O trabalho na forma social do capital e o trabalho como princípio educativo: uma articulação possível? Educação e Sociedade. v. 26, n. 90, jan/abr. p.239-265, 2005.

VIEIRA, P. A. OURIQUES, H. R. Elementos para crítica da centralidade do trabalho.

Pesquisa \& Debate, v. 17, n. 2, p. 149-172, 2006. 